\title{
Homicídios de jovens e segregação socioespacial em Londrina
}

\section{Youth homicides and socio-spatial segregation in Londrina}

\author{
Dione Lolis ${ }^{1}$
}

\section{Resumo}

O presente artigo analisa o quadro atual de violência homicida no País, bem como os fatores de risco e de vulnerabilidade de jovens residentes em Londrina (PR) a esse tipo de violência. Mostra também a incidência de mortes nos grupos jovens que residem em territórios de exclusão das capitais, das regiões metropolitanas e, num movimento mais recente, nas cidades do interior, como encontramos em Londrina. Além, disso, apresenta dados de pesquisa em que se avalia que a segregação socioespacial e os traços que assume na cidade são os aspectos centrais de risco e de vulnerabilidade de jovens à violência homicida. E, nesse intrincado contexto social em que vivem os jovens que mais sofrem esse tipo de violência, os componentes simbólicos importam tanto quanto os aspectos objetivos para desvendar o lugar destinado ao jovem na agenda das políticas públicas. Esses aspectos podem contribuir para a formulação de propostas que visem à redução dos níveis de morte violenta.

Palavras-chave: Violência. Risco e vulnerabilidade.Violência homicida. Segregação socioespacial. Juventude e cidade. Juventude e políticas públicas.

\begin{abstract}
This article examines the current state of murderous violence in the country, as well as risk factors and vulnerability of young people living in Londrina (PR) to this type of violence. The article also shows the incidence of deaths in younger age groups who live in areas of exclusion of the capitals, metropolitan areas and lately, in smaller cities, as found in Londrina. In addition, it presents research data showing that socio-spatial segregation and the features it introduces in the city are key aspects of risk and vulnerability of youth in homicidal violence. In this intricate social context in which young people who suffer the most with this type violence live, the symbolic components matter as much as the objective aspects to reveal the place destined for young people in the public policy agenda. These aspects may contribute to the formulation of proposals aimed at reducing levels of violent death.

Keywords: Violence. Risk and vulnerability. Homicidal violence. Socio-spatial segregation. Youth and city. Youth and public policy.
\end{abstract}

\footnotetext{
Professora Adjunta do Departamento de Serviço Social da UEL. Doutora em Sociologia pela UNESP, Campus de Araraquara. Mestre em Serviço Social pela PUC/SP. Especialista em Política Social pela UEL. Endereço: UEL/CESA/ Departamento de Serviço Social. Rodovia Celso Garcia Cid - PR 445, Km 380, Campus Universitário, Cx. Postal 6001, CEP 86055-900, Londrina - PR, Fone: (43) 33714245. E-mail - dionelolis@uel.br.
} 


\section{Introdução}

No Brasil, os grupos sociais mais vulneráveis e expostos aos homicídios, segundo as pesquisas atuais, compõem-se de jovens residentes em espaços urbanos denominados como bairros periféricos ${ }^{2}$ ou territórios de exclusão ${ }^{3}$ das capitais, das regiões metropolitanas e, num movimento mais recente, aqueles situados nas periferias das cidades médias do interior do País $>$ Esse dado foi apontado por Waiselfisz (2008) nos Mapas da Violência dos Municípios Brasileiros desde 2006.

Os homicídios de jovens tornaram-se nosso objeto de pesquisa a partir do momento em que cidades médias como Londrina ${ }^{4}$ passaram a representar as principais localidades de morte violenta, e atingindo as mais altas taxas de mortes por armas de fogo, comparáveis àquelas produzidas em conflitos humanos como a guerra. A situação agravou-se a ponto de Londrina ser considerada uma das mais violentas cidades do País neste início de década.

Enquanto a redução da taxa de mortalidade infantil na cidade fez crescer a esperança de vida ao nascer em 2,89 anos, passando de 68,48 anos em 1991 para 71,37 anos em 2000, os homicídios/ agressões passaram a ser a primeira causa de morte prematura desde 2001, e superou as mortes por acidentes de transporte/trânsito. Este e outros dados da Autarquia Municipal de Saúde de Londrina acerca da mortalidade no período de 1979 a 2004, na comparação entre os grupos populacionais jovens ${ }^{5}$ e os não jovens, mostram o brutal desequilíbrio entre o total de óbitos que são atribuíveis aos homicídios na cidade. Em 1979 os homicídios de jovens correspondiam a $12,8 \%$ do total e, em 2004, chegaram a 57,63\% do total dos homicídios na cidade, enquanto, no País, as mortes de jovens pelas mesmas causas ocorridas neste mesmo ano correspondiam a 39,7\% do total (apud LOLIS, 2008).

Esse quadro nos levou a pesquisar as mortes ocorridas em Londrina no período de 2000 a 2003, quando a situação mais se agravou. ${ }^{6}$ Em termos metodológicos, realizamos (1) uma discussão qualitativa, acerca dos elementos disponibilizados pela análise de documentos, bem como (2) uma significativa coleta de dados quantitativos ${ }^{7}$ as respeito dos homicídios por armas de fogo nos arquivos

2 A imagem da periferia esteve inicialmente marcada pela sua distância em relação ao centro, pela concentração de moradias precárias e sem oferta de serviços básicos e de deterioração da vida em cidades. Os estudos mais recentes buscam contemplar a diversidade ou a heterogeneidade existente internamente nesses espaços sociais (MOURA; ULTRAMARI, 1996). Hoje o significado de favela se confunde com os cenários de uma sociedade moderna e com a proliferação dos condomínios fechados de médio e alto padrão na periferia da cidade (autossegregação), conforme Caldeira (2003), que rompem com a divisão centro/ periferia nas cidades atuais e levam um novo padrão de periferia para os arrabaldes, ou subúrbios, ainda que não façam parte deles. Os afastamentos, portanto, não são qualificáveis apenas pelas distâncias físicas existentes, mas sim pelas condições sociais de vida que comprovam a nítida desigualdade entre os habitantes dessas regiões da cidade (ROLNIK, 1999; WACQÜANT, 2001b). Aqui adotamos os termos exclusão territorial e segregação socioespacial.

${ }^{3}$ O termo exclusão territorial possui estreita relação com a noção de exclusão social; considerando que tal compreensão abarca a soma de deficiências de várias ordens à vulnerabilidade e integra o escopo das políticas públicas (ROLNIK, 1999; OLIVEIRA, 2007). Estabelecer essa articulação permite perceber a existência de uma relação muito estreita entre a exclusão territorial e a violência urbana (cf. ROLNIK, 1999).

${ }^{4}$ Londrina é considerada uma cidade de médio para grande porte, e centro submetropolitano ou regional, com 506.701 habitantes (IBGE/2010), é a 4ª maior da Região Sul.

5 Sem desconsiderar o problema da classificação quantitativa, já que o conjunto de pessoas jovens não pode ser tratado de forma rígida, adotamos o recorte demográfico que considera os jovens como um grupo populacional que corresponde a uma determinada faixa etária, mas que é geralmente localizada entre 15 e 24 anos.

${ }^{6}$ Pesquisa para a tese de doutoramento em Sociologia na Universidade Estadual Paulista - UNESP/FCLAr.

7 Nos arquivos do Instituto Médico Legal de Londrina (IML/LD) levantamos dados dos seguintes documentos oficiais: Registro de Entrada, Laudo de Necropsia, Declaração de Óbito, Boletim de Ocorrência da Polícia Civil, laudos dos exames laboratoriais de avaliação de teor alcoólico, pesquisa toxicológica de outras drogas, exames para identificação do jovem assassinado (pelas digitais) e Boletim de Ocorrência da Polícia Militar. Consideramos em nossa coleta e análise todas as mortes de jovens entre 
do Instituto Médico Legal e na $1^{\text {a }}$ Vara Criminal. Consideramos também as principais discussões teóricas a respeito das atuais configurações da violência $^{8}$ e da criminalidade ${ }^{9}$ e enfatizamos suas relações com a segregação socioespacial ${ }^{10}-$ entendendo que a segregação, tanto social quanto espacial, é uma característica importante das cidades e que as regras que organizam o espaço urbano pautam-se em padrões de diferenciação social e de separação espacial (CALDEIRA, 2003).

Em nossa pesquisa, verificamos que no universo das 392 mortes violentas de jovens entre 15 e 24 anos, registradas no período de 2000 a 2003 em Londrina, entre elas os homicídios, suicídios e acidentes, 65 delas ocorreram no ano de 2000, outras 83 mortes no ano de 2001, 106 mortes em 2002 e 138 mortes foram registradas no ano de 2003. Entre as 392 mortes violentas, 254 delas tiveram como causa o homicídio e representam $64,8 \%$ do total das mortes. Essas mortes por homicídio foram produzidas por meio dos seguintes meios/instrumentos: 13 $(5,1 \%)$ por arma branca; $237(93,3 \%)$ por armas de fogo; $3(1,2 \%)$ por espancamento; e $1(0,4 \%)$ por estrangulamento. A ênfase em nossa análise foi dada às $237(93,3 \%)$ mortes de jovens em homicídios com o uso de armas de fogo.

Apresentamos aqui uma análise qualitativa das estatísticas dos homicídios de jovens que tiveram como meio/instrumento a arma de fogo e que consideram as características individuais e familiares dos jovens, em especial o gênero, fatores determinantes à ocorrência de homicídios, bem como aqueles aspectos que complementam o quadro de fatores de risco $^{11}$ e vulnerabilidade ${ }^{12}$, tais quais: $o$

15 e 24 anos (idade na data da morte) residentes em Londrina causadas por terceiros, de modo intencional e que tiveram como meio/instrumento as armas de fogo. A coleta abrangeu as informações gerais (cidade, data e horário da morte e entrada no IML/ LD), a caracterização do jovem (filiação, sexo, cor/etnia, estado civil, escolaridade, ocupação/atividade), o lugar de moradia, as condições e causas da morte (causa, descrição da morte, local dos disparos e da morte, tipo de local, endereço, meio/instrumento que produziu a morte e as lesões), os dados sobre os autores dos homicídios (dados pessoais), os dados relevantes apresentados à polícia pelos familiares e/ou declarantes sobre o jovem assassinado e sobre as circunstâncias que envolveram a morte e dados complementares dos demais documentos. Depois, recorremos à $1^{\mathrm{a}}$ Vara Criminal para levantar a situação dos processos de homicídio (julho de 2006) em que os autores foram denunciados.

Após a identificação dos bairros, das microrregiões e da região de moradia dos jovens assassinados por armas de fogo em Londrina, inserimos essas informações no mapa fornecido pela Secretaria de Obras e Instituto de Planejamento Urbano de Londrina e buscamos confrontar os dados com as informações da Companhia de Habitação de Londrina sobre a localização das favelas, assentamentos e ocupações irregulares (LOLIS, 2008).

${ }^{8}$ Conforme Michaud (2001, p. 10 - 11), "há violência quando, em uma situação de interação, um ou vários atores agem de maneira direta ou indireta, maciça ou esparsa, causando danos a uma ou a mais pessoas em graus variáveis, seja em sua integridade física, seja em sua integridade moral, em suas posses, ou em suas participações simbólicas e culturais".

9 Conjunto dos crimes (delitos) cometidos em um dado meio histórico e geográfico em dado período.

${ }^{10}$ A segregação é, sobretudo, um fenômeno relacional: só existe segregação de um grupo quando outro grupo se segrega ou é segregado. É nesse componente relacional que as medidas de segregação se baseiam, buscando medir o grau de isolamento de um determinado grupo social em relação a outro (TORRES, 2004). Para Marcuse (apud CALDEIRA, 2003), na segregação espacial reproduz-se um processo em que certos grupos populacionais são forçados de modo involuntário a se juntarem em uma dada área, tanto por mecanismos de mercado como por instrumentos institucionais e práticas efetivas de discriminação (TORRES, 2004; CARDIA, 2005).

${ }^{11} \mathrm{O}$ risco social é entendido aqui como a possibilidade que tem o indivíduo ou grupo de sofrer um dano futuro no seu equilíbrio vital, sendo que a manifestação desse dano está associada às condições objetivas e subjetivas desses mesmos indivíduos ou grupos. A variedade de sentidos do termo "risco" tem é o sinal de uma sociedade ávida por segurança e preocupada com a prevenção de diversas formas de entraves e de infelicidades no tocante à condição humana. Ações que envolvem a responsabilidade do Estado ou das coletividades locais encarregadas de velar pela segurança das populações, conforme Le Breton (apud ADORNO; BORDINI; LIMA, 1999).

${ }^{12}$ Para Oliveira (1995), as situações de vulnerabilidade podem ser geradas pela sociedade e geradas até pela forma como as pessoas lidam com as perdas, os conflitos, a morte, a separação, as rupturas. Não só os miseráveis são vulneráveis; a vulnerabilidade atinge ricos e pobres. Na análise dos indicadores de vulnerabilidade, que devem estar contidos na noção de exclusão territorial, valorizamos as condições etárias, de gênero e a situação de pobreza dos grupos sociais residentes em territórios precários. 
não acesso ao mercado formal de trabalho, à ocupação, à renda, à escola e o lugar de moradia. Todos eles represemtam possibilidades de acesso aos direitos institucionais e que, muitas vezes, se convertem em obstáculos para o acesso à justiça social.

Com base nesses dados, buscamos conhecer as representações construídas acerca dos jovens de Londrina, assassinados com armas de fogo, com o propósito de situar a evolução dessas mortes e identificar as situações de conflito que levaram esses jovens à morte, procurando entender a sua importância para a cidade. Recorremos às fontes orais em entrevistas ${ }^{13}$ com as principais autoridades públicas responsáveis pelas áreas de Segurança, Justiça e Ministério Público, que constantemente operam com a criminalidade, a juventude e os direitos e garantias Constitucionais.

Os dados indicam claramente o curso de um processo de juvenização da violência fatal na cidade, com traços tão alarmantes que se pode denominar como um "juvencídio". Cenário que justifica o estudo da perda prematura de vidas e os aspectos que mais contribuem para a violência homicida. Essa violência que não se traduz apenas pelo componente da idade, o que já é algo profundamente lamentável, mas também assume contornos de gênero, cor/etnia e lugar de moradia.

Pressupomos a segregação socioespacial, que reúne variáveis objetivas e subjetivas, e a sua ligação com a violência homicida é o que pressupomos como uma das principais formas de opressão que marginaliza, desumaniza e que leva a uma descomunal eliminação da vida de jovens por armas de fogo. Um processo que tem avançado para além das grandes metrópoles.

Outras variáveis aumentam a possibilidade da ocorrência de violência homicida de jovens, dentre elas, o uso abusivo de substâncias entorpecentes ou psicotrópicas $^{14}$ ilícitas, a participação na comercialização dessas drogas e o acesso às armas de fogo. Daí pode decorrer o envolvimento em outros atos infracionais (no caso de adolescentes) e crimes como furtos, roubos e em homicídios.

\section{Os jovens que Morrem por Homicídio com Armas de Fogo em Londrina}

A alta incidência de homicídios por arma de fogo nos indicadores de mortalidade de jovens londrinenses é o principal aspecto dos atuais padrões de violência. Configurações que não estão desarticuladas do contexto nacional e internacional.

Essa forte evidência para o aumento da violência homicida em Londrina é encontrada, principalmente, na taxa de 93,3\% das mortes de jovens por armas de fogo entre 2000 e 2003, número que estava acima da média do País (75\% em 2006) e que o elevou à $1^{\mathrm{a}}$ posição no mundo no ranking de mortes de jovens por armas de fogo dentre 65 países(WAISELFISZ, 2008).

\footnotetext{
${ }^{13}$ Entrevistamos o Delegado chefe da Polícia Federal (PF), o Delegado do Setor de Homicídios da Polícia Civil (PC), o Comandante do $5^{\circ}$ Batalhão da Polícia Militar (PM), o juiz da $1^{\text {a }}$ Vara Criminal de Londrina (JCM) (que concentra os crimes contra a pessoa), a promotora da $1^{\text {a }}$ Vara Criminal (PVC), o juiz da Vara da Infância e Juventude (JVIJ), a promotora da Vara da Infância e da Juventude (PVIJ), o promotor de Defesa dos Direitos e Garantias Constitucionais (PDGC), o promotor de Investigação Criminal (PIC), o diretor do Centro de Socioeducação I (CENSE I) e o diretor do Centro de Socioeducação II (CENSE II). As entrevistas ocorreram entre 21 de junho e 11 de julho de 2007, a partir de roteiro previamente elaborado (LOLIS, 2008).

${ }^{14}$ São drogas entorpecentes, para fins legais, substâncias como ópio, folhas de coca e preparações, a cocaína, seus sais e preparações, a maconha (Decreto Lei ${ }^{\circ}$ 891/1938), o talco, e outros produtos tóxicos (solventes químicos como éter sulfúrico, acetona e solventes orgânicos como o querosene e a gasolina) controlados pelo Ministério da Justiça (Portaria $n^{\circ}$ 1274/ 2003) e na nova Lei Antitóxicos (Lei n. 11.343/2006). A droga, como substância psicotrópica ou psicoativa, é aquela que ao entrar em contato com o organismo por diversas vias de administração, atuam no sistema nervoso central (SNC) produzindo alterações de comportamento, humor e cognição, conforme a OMS. Pode ter várias classificações pela ação no SNC: depressores da atividade; estimulantes da atividade; e perturbadores da atividade (CEBRID, 2003).
} 
A arma de fogo é o mais importante meio/ instrumento desse quadro de extermínio de jovens na cidade e mostra uma progressão. $\mathrm{O}$ seu uso na resolução dos conflitos vem sendo relacionado ao crime organizado ${ }^{15}$ em torno do tráfico de drogas. $\mathrm{O}$ crime organizado, o valor atribuído à posse de arma de fogo, a manutenção dos grupos armados ligados à estrutura do tráfico, estruturas de mando e obediência, o aumento do envolvimento de grupos com a delinquência e a intensificação da crueldade, leva ao agravo os conflitos interpessoais, que, muitas vezes, culminam em violência fatal onde a arma de fogo tornou-se um símbolo de poder e de "eficácia", na medida em que ela é muito mais letal do que a arma branca.

Os meios/instrumentos utilizados na prática do homicídio também são primordiais para indicar os padrões da atividade cultural de determinada sociedade. A análise dos homicídios e dos seus meios/instrumentos, bem como a sua vinculação ao crime organizado, mais especificamente ao tráfico de drogas e de armas, tendo em vista que estas armas, para chegar até os autores dos homicídios, dependem de uma estrutura que extrapola os limites dos territórios ${ }^{16}$ onde se desdobram as situações de conflito que culminam em morte. Esses deslocamentos e realocações na cidade permitem observar que o tráfico de drogas e de armas não se trata de um fenômeno conjuntural, mas que está ocorrendo uma integração gradual na estrutura produtiva local, vinculada a uma estrutura mundial (IANNI, 2004).
Quanto às características individuais dos jovens que morreram, verifica-se que o risco de morte em homicídios por armas de fogo para os homens é muito maior do que para as mulheres. Em Londrina, a taxa média para os homens jovens atingiu 92,36\% enquanto a média nacional foi de $90 \%$.

No grupo jovem que morreu em decorrência de homicídios por armas de fogo, os solteiros correspondem a $81 \%$, e isso mostra que poucos buscaram assumir compromissos, como a formação de uma nova família. Este resultado é até esperado tendo em vista a idade dos sujeitos. Os jovens solteiros pertencem ao grupo que apresenta maior risco de homicídio.

Os níveis de violência homicida contra os grupos definidos por cor de pele preta/negra vêm crescendo nos últimos tempos no País, atingindo o índice de $74 \%$ em 2004. No entanto, em Londrina predomina a morte de jovens de cor/etnia branca. Nossa hipótese é de que essa incidência se deve à diferença numérica deste grupo com relação aos demais.

A escolaridade é um importante indicador para análise das condições dos jovens que sofreram a violência homicida. Verificamos que a maior parte dos jovens não chegou a completar o ensino fundamental, e predominando aqueles que tinham de 4 a 7 anos de estudos e que não frequentavam mais a escola. A baixa escolarização, além do analfabetismo, está entre os principais indicadores que caracterizam a condição de vulnerabilidade. Essa característica social impede ou limita a mobilidade

\footnotetext{
${ }^{15}$ Para a ONU, “as organizações criminosas são aquelas que possuem vínculos hierárquicos, usam da violência, da corrupção e lavam dinheiro". O crime organizado deve considerar os aspectos econômicos e institucionais e envolve: o modus operandi dos autores de atos criminosos; a estrutura de sustentação e as ramificações do grupo; a hierarquia interna e a distribuição de funções; bem como o tempo de existência (OLIVEIRA, 2007).

${ }^{16} \mathrm{Na}$ atualidade, o território é definido como um produto das relações de poder que se formam num determinado espaço delimitado, ou ainda como a apropriação do espaço e da sua territorialidade, que reúne as características particulares de um território, seu conteúdo estrutural, sua materialidade própria e seu conteúdo imaterial, simbólico (RAFESTIN, 1993; LEFEBVRE, 1991). “O território são formas, mas o território usado são objetos e ações, sinônimo de espaço humano, espaço habitado" (SANTOS, 2005, p. 146). O termo território é então uma noção, pois "só se torna um conceito utilizável quando o considerarmos a partir do seu uso, a partir do momento em que o pensamos juntamente com aqueles atores que dele se utilizam" (SANTOS, 2000, p. 22). As territorialidades são itinerantes e podem ser ressignificadas.
} 
social de grupos jovens, pode se converter em obstáculo no acesso aos direitos sociais e, de algum modo, está relacionado à incidência da violência homicida de jovens por arma de fogo.

A ocupação/atividade é uma importante variável na identificação do grupo jovem que morreu em decorrência da violência homicida, pois o acesso ao emprego é um aspecto que compõe o conjunto de características que possibilitam o acesso à renda e que permite a mobilidade social. As principais ocupações/atividades exercidas pelos jovens eram diversificadas, todas elas em postos de trabalho de baixa remuneração e, provavelmente, situadas na informalidade. Talvez mais que qualquer outro grupo populacional, os jovens são os que mais enfrentam incertezas e os riscos do avanço acentuado no processo de expansão mercantil internacional nas últimas décadas.

As regiões de residência dos jovens assassinados por arma de fogo em Londrina, quando mapeadas e comparadas com base na localização dos endereços, permitem uma leitura genérica e macrorregionalizada dos dados. Três regiões concentram a maior parte das mortes de jovens no período. Constatamos que a Região Oeste, com $29,1 \%$ dos homicídios, a Região Norte, com $27,8 \%$ e a Região Leste, com $24,1 \%$, concentram a maior parte das mortes de jovens no período.

Nos dados citados, verificamos o movimento dos homicídios de jovens por arma de fogo, no período estudado, em cada uma das regiões. A Região Oeste (69) foi a que mais registrou esse tipo de violência na soma de todos os anos, com acentuado crescimento em 2002. A segunda maior frequência compreende à Região Norte (66), e foi a que mais apresentou assassinatos em 2003, duplicando a morte de jovens. A Região Leste (57) apresentou a terceira maior frequência de homicídios, em especial nos anos de 2002 e 2003. A Região Sul (27), está abaixo do índice das anteriores e a Região Centro (15) foi a que menos apresentou mortes no período. Nos Distritos, apenas 01 ocorrência foi registrada em Irerê. Ou seja, esse tipo de violência é eminentemente urbano. Ocorre que a distribuição dos homicídios não é homogênea.

A microrregionalização ${ }^{17}$ dos espaços permite uma aproximação ao lugar de moradia dos jovens, como também ajuda a observar os territórios de maior conflito. As microrregiões e os bairros que apresentam as maiores ocorrências de homicídios de jovens por arma de fogo coincidem com a existência do maior número de favelas, assentamentos e ocupações irregulares de Londrina, conforme dados da COHAB/LD (LONDRINA, 2006), com a prevalência de habitações consideradas subnormais. ${ }^{18}$

Os dados estatísticos evidenciam que o lugar de residência dos jovens londrinenses assassinados com arma de fogo demonstra a relação entre as áreas de exclusão territorial, com condições sociais desfavoráveis e de extrema pobreza como sendo os territórios de maior violência contra os jovens. Essa verificação foi confirmada pelos entrevistados, a exemplo deste: “[...] são pessoas que vivem na pobreza, juntamente com os traficantes de drogas [...] $90 \%$ são pessoas de baixa renda [...]" (PC, 25/06/2007).

Na Região Norte, a mais populosa da cidade e que passou pelo mais acelerado processo de urbanização a partir da década de 1980, as Microrregiões 1 e 2 (Figura 1) apresentam as maiores ocorrências de homicídios de jovens por arma de fogo. Esses dados coincidem com a existência do maior número

17 O mapa das Regiões, Microrregiões e bairros, adotado aqui é o utilizado pelo Orçamento Participativo, Lei Municipal de Londrina $n^{\circ} 9.306$ de 23/12/2003, fornecido em 24/11/2006 pela Prefeitura de Londrina para a pesquisa.

18 A favela é tipificada pelo IBGE (2002, p. 7) como "Setor Especial de Aglomerado Subnormal - Conjunto constituído por um mínimo de 51 domicílios, ocupando ou tendo ocupado até período recente um terreno de propriedade alheia (pública ou particular), dispostos, em geral, de forma desordenada e densa, em sua maioria com déficit de serviços públicos essenciais". 
de favelas, assentamentos e ocupações irregulares, somando, no período, 1.457 famílias residindo em condições precárias, principalmente no Jardim São Jorge, que apresentou o maior número de mortes.

Na Região Sul a concentração de homicídios de jovens se dá na Microrregião Sul 2 (Figura 1), que coincide com a localização de assentamentos urbanos, entre eles o Jardim União da Vitória - o maior assentamento de ex-moradores de favelas realizado pela COHAB/LD na década de $1980-$, e de outras ocupações espontâneas, com a incidência de habitações subnormais e sérios problemas de infraestrutura, como a falta de rede de esgoto. São 3.394 famílias nesta Microrregião vivendo em condições precárias e que, internamente, apresenta heterogeneidades.

A Região Leste, com 1.749 famílias vivendo em habitações subnormais, concentra o maior número de homicídios de jovens por arma de fogo na Microrregião Leste 3 (Figura 1). Essa localidade possui um agrupamento de ocupações irregulares e assentamentos, foco dos primeiros núcleos de favela de Londrina nos anos de 1950.

A Região Oeste tem duas Microrregiões com graves conflitos, as quais concentram os homicídios

de jovens por arma de fogo: a Microrregião Oeste 1 e a 4 (Figura 1), onde também estão localizadas as favelas, assentamentos e ocupações irregulares, com
2.041 famílias vivendo em situação precária. $\mathrm{Na}$ Microrregião Oeste 4, as favelas e assentamentos existem há mais tempo na Região, como o Jardim Nossa Senhora da Paz e o Jardim Leste Oeste, nesse território foram registrados grandes conflitos em torno do tráfico de drogas. Na Microrregião Oeste 1 estão as ocupações do Jardim João Turquino e do Jardim Maracanã, que surgiram na década de 1990.

A Região Centro - que tem a maior concentração populacional por $\mathrm{m}^{2}$ - registrou o menor número de homicídios de jovens por arma de fogo, representada pela Microrregião Centro 2 (Figura 1), e os jovens que morreram residiam nas pequenas favelas e no seu entorno.

Esses registros de mortes violentas revelam a maior incidência nos lugares onde são precárias as condições sociais de existência coletiva e onde a qualidade de vida é acentuadamente degradada. As evidências indicam que o risco do jovem ser vítima de homicídio por armas de fogo é superior entre aqueles que habitam áreas, regiões ou bairros com défices sociais e de infraestrutura urbana, bem como no local onde o tráfico de drogas encontra as condições propícias para a sua existência.

A localização desses homicídios de jovens por arma de fogo por Região, Microrregião da cidade e a sua distribuição nos anos pesquisados pode ser observada no mapa a seguir (Figura 1). 
Figura 1 - Distribuição dos homicídios de jovens por arma de fogo em Londrina por Região e Microrregião de 2000 a 2003.

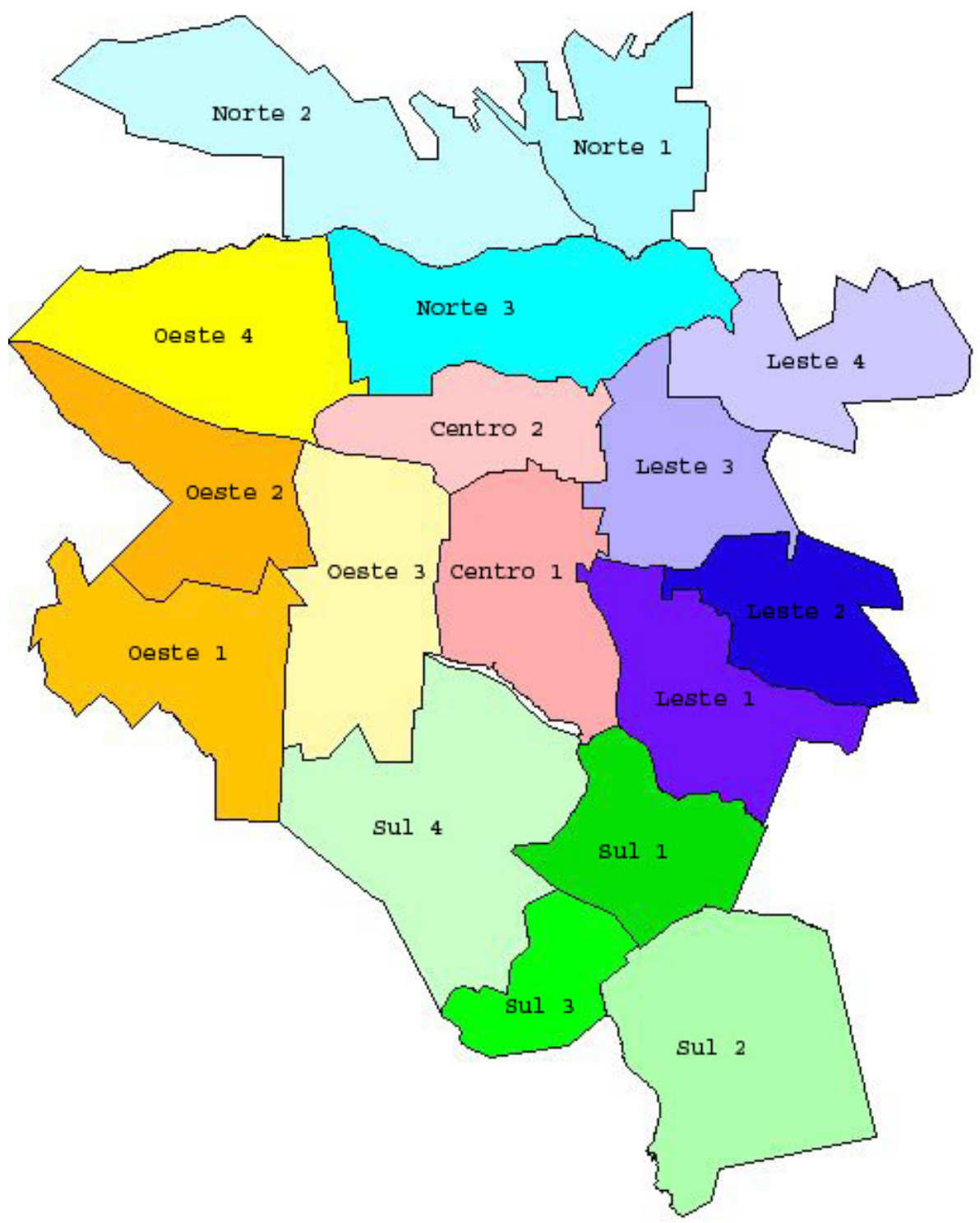

Fonte: Instituto Médico Legal de Londrina - IML/LD. Dados de 2000 a 2003, Mapa com composição das Regiões, Microrregiões e bairros, adotada pelo Orçamento Participativo, fornecido em 24/11/2006 pela Prefeitura de Londrina. Dados coletados e organizados por Dione Lolis (2008).

O local de ocorrência dos disparos de arma de fogo que levaram o jovem à morte está em grande parte circunscrito à região de moradia do jovem violentado e os dados da autoria indicam que o autor (ou autores) era uma pessoa conhecida ou do convívio social do jovem.
No confronto entre os números de homicídios de jovens por arma de fogo e os lugares de moradia por região, microrregião de Londrina, confirmamos que a maioria que morre em decorrência dos homicídios por arma de fogo é composta de homens jovens, pobres, moradores de territórios marcados pelas 
condições de vulnerabilidade social. Territórios onde eles convivem a maior parte do tempo de suas vidas em contato com violências de todo tipo, inclusive a morte, em contraste com os acessos proporcionados aos grupos de maior renda.

\section{Os Jovens nos Espaços Segregados da Cidade e a Vulnerabilidade à Violência Homicida}

A violência e a criminalidade são problemas que vem sendo relacionados às transformações vertiginosas ocorridas no cotidiano das cidades brasileiras em nossa época, que não exclusividade nacional, mas que apresenta especificidades locais e regionais. Assim como à crise de sociabilidade, seguidas dos processos culturais que acentuam o individualismo e a competitividade, sobrepõem o indivíduo sobre a sociedade, bem como sobrepõe os pequenos grupos sobre a coletividade e têm como uma das principais características a banalização da vida e a busca de consumir a qualquer custo os bens materiais e imateriais desigualmente distribuídos nas sociedades modernas fragmentadas.

A precariedade da existência social, que influencia uma percepção de realidade como um conjunto de produtos para o consumo imediato e isolado, mostra um mundo inconsistente onde o processo de socialização é frouxo, débil e imediato, e revela a fragilidade e a fragmentação da existência dos grupos humanos, em particular, dos jovens em certos contextos (BAUMAN, 2001).

Nas sociedades modernas, o homicídio pode ser considerado a expressão máxima da exacerbação dos conflitos das relações interpessoais. Durkheim (1978) já afirmava que o homicídio traduzia-se no mais grave dos crimes, o mais violento atentado à consciência coletiva e causador de forte indignação. E se as normas se afrouxam, ocorre o esfacelamento de uma moral compartilhada pela sociedade. Para Elias (1993), o relaxamento nas restrições sociais ou o afrouxamento do monopólio da violência física legítima do Estado pode elevar o risco do recurso ao ato violento na sua resolução.
Nessa liberação dos vínculos e controles sociais dos indivíduos uma questão central define-se pela existência de uma crise da cidadania moderna, em seus múltiplos aspectos. Para Martuccelli (1999), no prolongamento da juventude, o recurso à violência é resultado da tensão entre um modelo normativo desconectado dos fatos e sua fraca vinculação social.

Assim, a violência encontra terreno fértil na apatia, na ausência de saídas, na quebra dos valores de tolerância e solidariedade. Os impasses da modernidade geram diversas formas de culto à violência como alternativas de solução para os problemas imediatos, adquirindo novas formas e novos conteúdos, sob o aspecto de violência gratuita. E, ainda que os jovens manifestem algum otimismo, conhecem as suas fragilidades e a falta de futuro nesse meio.

Nesse contexto, os jovens são usualmente apontados como os principais protagonistas dessas mudanças; ora como violentadores, ora como principais violentados. Paradoxalmente, ao mesmo tempo em que o jovem passa a ser reconhecido como portador de vontade própria, que precisa ser respeitado nos mais distintos aspectos da vida pessoal independente: escolha profissional, vestuário, consumo, lazer, iniciação e atividade sexual, "essa mesma autonomia é vista como fonte de riscos, entre os quais, talvez o mais temido, seja o envolvimento com o mundo do crime e da violência" (ADORNO; BORDINI; LIMA, 1999, p. 64).

Com a progressão da violência nos dias atuais, prevalece uma atitude ambígua na sociedade em relação aos jovens. De um lado, os indivíduos se sentem responsáveis pelo que ocorre à juventude, de outro, há um apelo velado para responsabilizar os jovens por uma série de problemas cotidianos, principalmente os relacionados à violência criminal. O que leva a pensar que a violência cometida por jovens parece preocupar mais alguns setores da sociedade brasileira do que a violência por eles vivenciada em seu cotidiano sem as perspectivas de ascensão social. Criou-se uma espécie de mito 
da "alta periculosidade" dos jovens infratores, que abre espaço para o discurso do medo amplamente difundido pelos meios de comunicação. Com isso, para muitos, permanece a crença de que o aumento da repressão parece ser a solução ideal para resolver a problemática da insegurança urbana.

Os jovens no mundo ocidental pertencem a um dos grupos mais vulneráveis ao risco social. Para Le Breton, as formas de risco alcançam múltiplos atores e múltiplas formas de atividade. No entanto, alguns grupos, como os jovens, apresentam especificidades que os tornam mais suscetíveis a esse risco. Isto por que o jovem experimenta repentinas transformações na eminência de entrar no mundo adulto e costuma adotar inúmeras condutas de risco (apud ADORNO; BORDINI; LIMA, 1999, p. 73). Os riscos da juventude são, por um lado,

[...] uma construção ideológica de sociedades que não querem explicitar os perigos que geram as decisões dos atores políticos e econômicos, e por outro, são os efeitos reais no âmbito individual de ser 'arremessado fora' de uma sociedade idealmente ordenada e protetora (MALUF, 2002, p. 5).

Os condenados históricos de sempre, crescem nos territórios de exclusão e formam o contingente da economia informal, com isso ascendem às redes do delito, não o do furto, mas o da morte. Convertidos pela intrincada associação entre sobrevivência e sociedade criminal, envolvidos na rede do delito e da "narcoeconomia", ${ }^{19}$ nem cidadãos e nem produtores, os grupos juvenis, considerados portadores de uma violência de novo tipo e relacionada a uma nova pobreza (CACCIA-BAVA, 2004), formam novas lealdades e novos espaços de "sociabilidades e afetividades substitutas" onde passam a conviver a maior parte do tempo em contato implacável com a morte, diante do risco e do terror anunciado (MALUF, 2002).

A atitude de desafiar a morte faz parte do universo dos jovens que morreram em decorrência dos homicídios por armas de fogo em Londrina. A ameaça de morte pode ser entendida como um dado cotidiano e sempre à espreita para esses grupos sociais. A representação construída pelas autoridades é de que os jovens têm consciência do risco de morrer a qualquer momento, mas que a vida para eles parece não ter importância e que "faz parte desse jogo matar ou morrer" (MPVIJ, 2007).

A motivação que leva o jovem a viver esses riscos a cometer um homicídio e até mesmo, assumir a autoria de um assassinato cometido por outra pessoa, geralmente pelo adulto, para escapar da penalização parece estar ligada a um modelo de "masculinidade 'desafiadora' ou negadora de qualquer poder ou autoridade superior" (ZALUAR, 2004, p. 260). Para Zaluar, esse equilíbrio de tensões, que poderia conter a violência, resultaria "da boa proporção entre orgulho de não se submeter a nenhum compromisso exterior ou poder superior; típico do etos guerreiro, e o orgulho advindo do autocontrole, próprio da sociedade domesticada" (ZALUAR, 2004, p. 260), que parece não ter atingido as pessoas, classes sociais ou sociedades com a mesma intensidade. Também a exacerbação dos localismos, seja de Estados, cidades ou bairros, pode estar contribuindo para o retrocesso da civilidade. Assim, encarar o aumento da violência de homens jovens como justificativa para a necessária afirmação das pequenas diferenças locais e grupais pode, também, fazer com que percamos a dimensão do que é um processo macrossocial.

\footnotetext{
19 As expressões "narcoeconomia" e "narcotráfico" se referem ao tráfico de narcóticos, de drogas. O narcotráfico transita entre o mundo da legalidade e da ilegalidade, com ramificações em diversos países e penetra em todas as esferas de poder estatal, empresariais e sociais. Ele é o responsável pelo cultivo, produção, refino, embalamento, distribuição, transporte, redistribuição e comércio dos narcóticos. É uma estrutura que emprega centenas de milhares de membros organizados e alguns milhões de trabalhadores na produção da matéria-prima no mundo. Um negócio que inclui tráfico de drogas, vendas de armas, "lavagem de dinheiro", prostituição, tráfico de órgãos humanos, suborno, extorsão, controle de áreas utilizando métodos violentos de terror com uma estrutura paramilitar (Ver RODRIGUES, 2002; ARBEX-JUNIOR, 2001).
} 
Para os nossos entrevistados, o jovem pode ser facilmente convencido a assumir a culpa por um ato que não cometeu com o objetivo de ser reconhecido na sua comunidade, ter força e poder, como também para se "espelhar" ou obedecer às regras daquele que está na atividade há mais tempo e possui posição de maior poder na estrutura do comércio de drogas ilícitas. Ele quer ser importante no grupo e ter status de "bandido perigoso", "bandido bom". Agregando a esta disposição as razões econômicas, para a aquisição de bens de consumo para própria sobrevivência e a da família (comida, moradia) e para o consumo de bens materiais e simbólicos, que são definidos como importantes para o grupo de referência (roupas e calçados de determinada marca; eletrônicos; drogas legais e ilegais; festas).

A perda da liberdade, paradoxalmente, é, em algumas situações, uma forma de sobrevivência dos jovens envolvidos em atos infracionais. No interior das instituições onde cumprem medida socioeducativa ou de internação, os adolescentes ameaçados de morte passam a ser os "presos seguros", que são separados e vigiados para a sua proteção física.

Desse modo, a atuação do crime organizado sistematiza novas questões para a abordagem da Justiça da Infância e da Juventude, bem como questões para a Justiça Penal. Nele, tudo funciona na base do segredo, da "lei do silêncio", "cuja transgressão é severamente punida, não raro com a morte de um suspeito, o que arrasta atrás de si uma cadeia de tantos outros, suposta ou efetivamente comprometida com a ruptura do pacto" (ADORNO, 1998, p. 38). Isso dilui a materialidade da infração e atenua a identificação da responsabilidade penal.

Ajulgar pelos indícios que colhemos nos registros das apreensões feitas pelas polícias no Paraná, ${ }^{20}$ pode-se afirmar que os jovens estão cada vez mais envolvidos com o tráfico de drogas. Porém, os dados nos parecem incompletos para atribuir o ônus pelo aumento do tráfico exclusivamente a eles, tendo em vista que esse grupo é muito mais visado pela polícia, transporta pequenas quantias de drogas em mochilas, sempre de ônibus, conduz as drogas para outros traficantes maiores. Ademais, a exemplo do que ocorre na situação dos homicídios, esses jovens podem estar assumindo a autoria de uma prática cometida por um adulto, ocultando o "esquema".

Esses jovens que servem ao tráfico como "mulas" correm elevados riscos para transportar as drogas e, ao que tudo indica, têm muito pouco a ganhar com essa atividade. Para Zaluar (2004), a dinâmica própria do tráfico de drogas e as atrações que ele exerce, em termos de cálculo racional, da "ambição" quase ilusória de "ganhar muito dinheiro" ou "ganhar fácil" e perder fácil, dos valores de um etos de masculinidade que seriam atingidos por meio da criminalidade, são alternativas para os jovens pobres. E aquele que entra para esse mundo, dificilmente sai dele.

Na hierarquia do tráfico, as disposições de mando e obediência fazem parte da dinâmica em que os chefes - os "cabeças", os "homens de frente" - se diferenciam dos que obedecem ao seu comando, assim como as oposições são grandes entre aqueles que ganham dinheiro como donos de "boca-defumo", ou "pontos", e os que trabalham para o chefe como vendedores ou como "mulas".

O crime organizado em torno do tráfico de drogas em Londrina, estrutura da qual fazem parte os seguintes elementos: corrupção policial, hierarquia no tráfico, armas de fogo e "sociabilidade violenta", é a fonte de suprimento de armas que servem como meio/instrumento nos homicídios de jovens, sejam elas advindas do contrabando, originadas dos furtos e roubos, legais ou ilegais, compradas, emprestadas

\footnotetext{
${ }^{20}$ Estatísticas que coletamos no Mapeamento dos resultados contra o narcotráfico realizado pelas polícias Militar, Civil, Federal e Rodoviária Federal de 16/06/2003 a 30/11/2007, no site do Programa de Narcodenúncia 181, das Secretarias de Estado da Justiça e da Cidadania e de Estado da Segurança Pública (apud LOLIS, 2008).
} 
ou alugadas por traficantes. Essas armas usadas por grupos jovens ligados ao comércio de drogas servem como recurso para manter e afirmar o seu poder territorial e permitir o livre comércio de drogas, enfrentando para isso a polícia e as gangues rivais. Isso tem levado comunidades a um estado de permanente conflito.

Londrina é considerada uma rota importante no tráfico internacional de drogas, principalmente de maconha, que é bastante comum, de papelotes de cocaína e de crack; que liga os grandes centros produtores, como a Colômbia, Bolívia e Peru, passa pela Argentina e Paraguai, chegando ao Brasil via cidades fronteiriças como Foz do Iguaçu, a principal, e por Guaíra, para abastecer o mercado da Região Sudeste e para a exportação via Porto de Paranaguá. É a única cidade do Paraná e da Região Sul do Brasil que acumula as funções de "Ponto de Trânsito" e de "Centro de Processamento" de cocaína, pela sua importância geográfica e logística estratégica, além de ser um centro consumidor importante (MACHADO, 2002; ARGENTINA, 2007). Isso indica que Londrina oferece as condições logísticas necessárias para a lavagem do dinheiro do tráfico e para a existência de centros de processamento de cocaína e fabricação de outras drogas. Há razões para que essa modalidade de organização tenha se instalado na cidade, ainda que em moldes das grandes metrópoles brasileiras.

O contrabando de drogas e, no seu encalço, o comércio ilegal de armas de fogo, faz parte da estrutura reprodutiva das mercadorias e se integra à cadeia reprodutiva da violência, ao se considerar o número de homicídios que tiveram como meio/ instrumento a arma de fogo. A sociabilidade vem sendo ameaçada pelo crime organizado e por esses grupos armados.

O aumento do consumo de cocaína na cidade também ocorre com a sua difusão por meio do crack, na sua versão mais impura, e que pode ser encontrado com preço mais baixo no mercado das drogas ilícitas. Inclusive, segundo as opiniões dos entrevistados, o aumento da violência está relacionado essencialmente aos conflitos decorrentes do comércio e do consumo de drogas como o crack, droga predominante entre os usuários nos últimos anos, que coincide com o período em que mais ocorreram homicídios de jovens na cidade. E, por isso, esta relação será sempre retomada aqui. Eles deixam bem claro esta relação:

Podemos afirmar, com base na experiência frente à Vara da Infância e Juventude, que a maioria das mortes estão relacionadas com assassinato e drogas, através de depoimentos dos próprios adolescentes envolvidos(JVIJ, 2007).

O jovem é atraído para o tráfico de drogas ainda na infância, e, como usuário, é capaz de se submeter às regras impostas pelo traficante para manter a dependência, a sobrevivência e para consumir outros bens. Desse modo, além de estar sujeito à vontade de outrem, a uma hierarquia e a alguma espécie de poder, submete-se também à vontade incontrolável de consumir a droga com frequência, principalmente se esta for o crack, levando-o a usar todo o estoque que possui da droga ou de dinheiro para consegui-la, o que exige um investimento monetário muito maior para satisfazer a dependência.

E os traficantes, muito atentos a isso acabam conquistando essa legião de jovens, pelo menos boa parte dos jovens, para que eles possam também traficar" (PDGC, 2007). "Eles são usuários, são 'mulas', entram no trafico de entorpecentes por conta do uso. Não tem como o traficante seduzir o adolescente só pela 'grana'. [...] Eu tenho dois moleques aqui com 10 anos de idade que eu não sei o que eu faço; não para com a família, vive no tráfico de entorpecentes, entra e sai do Abrigo(PVIJ, 2007).

No tráfico de drogas existem regras comuns, mas as formas de aplicá-las são diferentes. Essas regras no tráfico são estabelecidas para que o comércio ilegal de drogas possa ocorrer de modo satisfatório e lucrativo (FEFFERMANN, 2006). As relações de poder seguem uma ordem assimétrica e o domínio se dá com base nos sentimentos de medo, lealdade, confiança, gratidão ou de uma dívida contraída. A 
intimidação por meio de armas também é uma forma de manutenção de poder.

A arma de fogo exerce grande atração sobre os jovens envolvidos em atos de infração em Londrina. Ela é símbolo de poder, de liderança, de status, de orgulho, de êxtase, de endeusamento. O contato e a disponibilidade de armas faz com que os jovens se aproximem delas desde cedo e isso banaliza o fato de portá-las. "É um empoderamento que você dá para o adolescente quando você põe uma arma na mão dele. Ele é Deus!” (PVIJ, 2007).

Os grupos jovens buscam a ascensão entre os pares e na comunidade de forma rápida, por meio dos atrativos oferecidos pela sociedade de consumo e pelas possibilidades de afirmação de uma identidade masculina associada à honra e à virilidade, que são "modos concretos de inserção e de localização sociais em uma era caracterizada pelo cercamento e cerceamento das opções de escolha pessoal" (ZALUAR, 2004, p. 102). Isto se daria pela explosão de individualismo que, para os jovens, se manifesta na valorização de bens como a arma, a droga, o dinheiro, as roupas bonitas e na disposição para matar.

Essa percepção sobre o jovem e a sua necessidade de consumo, de inserção em um grupo, é verificada nas entrevistas:

[...] o consumismo, o iPOD, o MP3, um tênis Nike, muito bem vestido [...] faz com que eles, para poderem se integrar nos grupos, tenham as coisas que a mídia está mostrando [...] (PVIJ, 2007).

A mão-de-obra hoje é muito barata; ela é subqualificada, e isso não cria estímulos para aqueles que precisam trabalhar e acabam entrando no tráfico. Isso porque ele tem que comprar ou tem que furtar um tênis da Nike, de último tipo, tem que ter um celular muito bom, e não quer ser visto como um fracassado [...]. Então, esse contexto acaba explicando porque tantos jovens morrem nessa faixa etária (PDGC, 2007).

Muitos deles, nesse mundo consumista em que vivemos, acabam roubando para colocar um tênis novo no pé para ir para uma festa, para beber, mas a grande maioria, particularmente dos meninos que eu conheço, o dinheiro quase todo que ele 'faz' em roubo, acaba usando em droga, acaba fumando [crack]. Consome rapidamente e acaba alimentando o mundo do tráfico (CENSE II, 2007).

O individualismo, o consumismo e utilitarismo, presentes na modernidade, levam grupos jovens a viverem intensamente, numa atitude desafiadora, já que as perspectivas de acesso aos bens simbólicos e materiais são remotas. Esse jeito de viver do jovem o conduz ao crime organizado, em especial, ao narcotráfico, que captura os moradores em territórios de exclusão. A banalização da vida passa a ser um caminho e a arma de fogo torna-se um símbolo de poder sobre ela.

$\mathrm{Na}$ mesma direção, alguns pesquisadores consideram que, para o jovem da favela, a preferência por arma de fogo é por poder, status, riqueza material e também para a sensação de identidade com o grupo e a comunidade, além dos objetivos de acumular forças (medida de força), intimidar (impor medo) e dominar (exercer o controle). $\mathrm{O}$ acesso à arma, a entrada para a criminalidade, aparece como um caminho de curto prazo para a rápida ascensão, obtenção de bens de consumo, prestígio, poder, dinheiro, mulheres, respeito. A arma é um elemento fundamental na construção de masculinidade, relacionada à imagem de guerreiro, à virilidade, à coragem. A manifestação de poder e de mando por meio da imposição do medo parece ser o objetivo que leva o jovem a portar uma arma e a valorizá-la. Essa simbologia interfere, inclusive, nos preços das armas de fogo quando desviadas e negociadas no crime e tornam-se mercadorias políticas (RIVERO, 2005). Para muitos homens jovens residentes em territórios precários, a posse de arma está associada fortemente com uma escolha de vida importante e quase irreversível, como a entrada para o tráfico de drogas (LESSING, 2005).

No contexto do tráfico de drogas, a transgressão das regras estabelecidas pelo grupo que domina o comércio de drogas ilícitas em certo território (físico ou simbólico) e a forma de resolução de 
conflitos culmina, muitas vezes, na eliminação da vida do oponente. Matar para sobreviver ou viver para esperar a morte, a própria e a dos outros, parece ser a expectativa dominante em meio à luta pela sobrevivência. Uma violência oriunda da necessidade que a criminalidade organizada tem de difundir o medo para manter o controle social e de territórios entre traficantes rivais, que sempre busca a expansão dos negócios.

As disputas de grupos do tráfico de drogas por um território se dão entre cidades, bairros e locais do próprio bairro, em torno dos pontos de comercialização dessas drogas e de seus "donos". Ocorrem "porque dentro do bairro pode haver a guerra por causa dos pontos [...]. A 'biqueira' é o ponto de drogas dentro do bairro [...]. Cada 'biqueira' tem um 'dono'. Então, ali ele pode perder a área. Se outro invadir, ele vai matar aquele outro" (CENSE II, 2007). Outras opiniões são muito próximas:

O homicídio está muito ligado às drogas, ao acerto de contas. Por que a maioria é por arma de fogo? É óbvio, porque para o bandido valem três coisas importantes: dinheiro, droga e arma, e obviamente os acertos de contas são geralmente com armas de fogo [...]. Muitas pessoas morrem antes de chegar o fim do processo, porque são acertos de contas, brigas de gangues. Dos homicídios de Londrina, de 100 nós teríamos apenas 10 ou 15 que não tivesse problema de drogas ou acerto de contas (JVC, 2007).

$\mathrm{Ou}$ os jovens são mortos porque num determinado momento eles servem para o tráfico de drogas e a partir do momento que delatam algum crime ou que querem sair do esquema, também são mortos. Isso quando não são mortos na disputa por ponto de droga, ou porque eram usuários ou porque tiveram qualquer atrito ou controvérsia com pessoas relacionadas ao tráfico [...]. Até uma briga de vizinho às vezes pode ocasionar uma morte, porque é a banalização da vida humana e o traficante, para demarcar território, demonstrar que tem poder, não vai pensar duas vezes [em matar] (MPVC, 2007).

Para não perder o território, a eliminação do oponente é um recurso para a manutenção do poder. Isso indica que os conflitos cotidianos extrapolam o bairro e se estende para instituições, como as unidades de socioeducação e as prisões, assim formam outros territórios de poder e territorialidades que ultrapassam o lugar de moradia, mas que ainda se dão a partir dele e, fazendo da vingança uma forma de socialização.

Essa violência envolve agressões e homicídios cometidos no interior da hierarquia de vendedores como forma de reforço dos códigos normativos, com retaliações violentas dos traficantes, eliminação de informantes e punições por não conseguir quitar débitos com vendedores. As opiniões dos entrevistados são de que os jovens banalizam a vida e a morte, isso se torna uma "condição que para ele é uma coisa natural cometer o ato. Porque ele viveu muito nessa vida e para ele isso não é uma coisa muito grande. Eu acho que para muitos deles é uma questão até de sobrevivência" (CENSE II, 2007). Representações apoiadas na categoria utilitarista de "limpeza social" dos seres considerados supérfluos, e que estabelecem a violência por meio de processos excludentes, tipificando-se assim a violência instrumental. $^{21}$

A intensificação da crueldade e da imposição de sofrimento às pessoas violentadas por homicídios é uma verificação feita nos Laudos do IML/LD e nos $\mathrm{BO} / \mathrm{PC}$, isso nos chamou a atenção. Aspecto citado pela promotora Criminal:

A gente vê homicídios aqui em Londrina com requintes de crueldade. São tiros na cara, demonstrando execução, "amarramento" de mãos e ocultação [de cadáver] nos rios, às vezes o homicídio acompanhado de violência sexual [...]. Características de execução. E devo anotar o seguinte: caguetou o ponto de droga, ficou devendo $\mathrm{R} \$ 10,00$ para o ponto de droga, não honrou qualquer dívida ou qualquer compromisso com o tráfico de drogas, é morte! Seja adolescente ou jovem envolvido com o tráfico, seja usuário (MPVC, 2007).

${ }^{21}$ Instrumental porque a violência é um recurso utilizado para obter ganhos comerciais no tráfico de drogas, no contrabando de armas e em suas atividades ilegais praticadas no chamado "crime do negócio" (ZALUAR, 2004). 
A humilhação pública por quaisquer ínfimos motivos, a defesa de enfrentar a morte para defender a sua família, propriedade, reputação, honra (longe da noção de honra das sociedades tradicionais), e até a determinação de matar para "não levar desaforo para casa” (ZALUAR, 2004; PORTO, 2001), também parecem ser motivos para os desfechos fatais.

A violência também gera medo e insegurança. $O$ medo tem a capacidade de reproduzir a violência. E, sendo o medo da morte o maior de todos os medos, principalmente o medo do assassinato, imprevisível e fútil, também por sermos humanos, temos a capacidade de compreender que ele nos rodeia. Mas o sentimento em relação à morte é diferenciado em cada grupo e sociedade. Para Elias (1993), o que aparenta ser algo natural e imutável para os seus membros, é variável e específico e, portanto, fruto de certa aprendizagem.

Sendo o homicídio irreproduzível (pela unicidade e singularidade da pessoa humana) e irreversível, a ação se converte em uma espécie de "ato absoluto" ou como "o acontecimento por excelência". Além de singular, ele transforma o transgressor em "sujeito absoluto" e, por sua ação, produz alterações definitivas e irrevogáveis na superfície do mundo (FOUCAULT, 2000). Matar uma pessoa é, de certa forma, romper com a humanidade, ficar fora dela (CARRARA, 1991). E, uma vez quebrada a barreira do proibido, o assassinato para alguns pode ser um ato de prazer na repetição e a afirmação de poder sobre o outro, de domínio sobre a vida e a morte; momento em que "a violência torna-se então habitual e banal, algo com que as pessoas se habituam a conviver, perdendo assim a sensibilização adquirida num longo processo de socialização" (ZALUAR, 2004, p. 387).

Esses jovens, em suas trajetórias de vida, têm ou tiveram uma vida miserável e problemas de violência quando crianças, em casa ou na rua. Com esse percurso, eles têm muita dificuldade em mudar de vida e acabam, muitas vezes, sendo violentadores de outros e sofrendo a violência homicida. O ingresso na criminalidade, além de ser um modo de sobreviver, é uma forma de fuga da realidade. Nisso quebram-se os laços familiares e vicinais, estabelecendo-se outras relações interpessoais que substituem as redes tradicionais.

De acordo com essas opiniões e a ideia de Passetti (1999), essas crianças e jovens violentadas muito provavelmente reproduzirão no futuro essa situação, dando continuidade à "sociabilidade autoritária". Desse modo, são como violentados e não como vitimizados que eles deverão ser entendidos na reprodução da sociabilidade autoritária.

É importante também considerar que a estratégia do crime organizado está na contextura espacial hierarquizada e que a territorialização das favelas e outros espaços de exclusão social, das grandes e médias cidades, é um fator de fragmentação social, política e espacial do tecido urbano.

As cidades com as piores condições de segregação socioespacial, e não os mais pobres, são aquelas que apresentam maior violência. As cidades com melhor renda concentram mais violência. "Londrina é uma cidade riquíssima para os padrões brasileiros, mas é violenta" (ZALUAR apud GOIS, 2004). A concentração de pessoas nas regiões metropolitanas, sem emprego e sem alternativas para geração de renda, facilitaria a sua vinculação em atividades do tráfico de drogas, sobretudo no grupo jovem. Nos encraves urbanos segregados, o distanciamento dos grupos sociais ali residentes se desenha para além do afastamento geográfico em relação às demais áreas urbanizadas, acentuando o estranhamento decorrente das suas características físicas e das dificuldades de acesso aos serviços (ROLNIK, 1999).

Desse modo, como sustenta Wacqüant (2001b), a segregação socioespacial intensifica as dificuldades ao concentrar, em encraves urbanos isolados, grupos sociais com graves privações de ordem material e simbólica. Diante do desemprego e subemprego crônicos, determinados grupos populacionais que se 
encontram "enclausurados" em espaços segregados das cidades e com reduzidas perspectivas de futuro, são levados a procurar a assistência social pública e outras atividades geradoras de renda não declaradas ou indeclaráveis, como o mais perigoso e lucrativo de todos: a venda de drogas ilegais, que envolve cada vez mais crianças e jovens. Então, o território não é neutro e o seu arranjo histórico e atual tem uma influência inegável sobre a produção e a reprodução da segregação, manifesta principalmente a violência, particularmente, a violência dos homicídios de jovens.

Assim, entendendo que a segregação socioespacial é uma representação tanto física como simbólica e que decorre de fenômenos diversos, obtém-se uma visão mais abrangente das condições de vida e dos riscos sociais que atingem os grupos populacionais, especialmente os jovens, bem como das possibilidades de sua superação ou minimização. É no confronto entre as características individuais e familiares dos indivíduos com as suas possibilidades de desfrute dos bens e serviços ofertados pelo Estado, sociedade e mercado que se definem as suas efetivas condições de vida e possibilidades de mobilidade social. Neste caso, trata-se aqui de uma segregação fruto da imposição de um contexto social, que nada tem a ver com uma escolha individual e subjetiva. Desse modo, sendo a segregação um fenômeno relacional, pode ser dada como evidência que a segregação residencial colabora para o aumento e/ ou a perpetuação da pobreza. A pobreza, a violência e a criminalidade serviriam como justificativas para o isolamento e a especulação.

São territórios onde o traficante de drogas tem status de herói na vida de jovens envolvidos nesse tipo de comércio e onde a atitude definida como criminosa não é impedimento para que indivíduos ou grupos de pessoas tenham acesso a uma sociedade de consumo universal. Nesse caso, a necessidade de reconhecimento, de luta contra a humilhação não só contra a privação e a fome é um fato antropológico fundamental. Tantoéque as frustrações ehumilhações produzidas em nossa sociedade têm motivado ações que escapam à regra e podem ser motivos para os desfechos fatais. Na avaliação de Bourdieu (apud BAUMAN, 2008, p.7), "talvez não exista pior privação, pior carência, que a dos perdedores na luta simbólica por reconhecimento, por acesso a uma existência socialmente reconhecida, em suma, por humanidade".

O processo de fragmentação, segregação residencial e o aprofundamento das distâncias sociais entre os habitantes das regiões citadinas, expõe e agrava conflitos de diferentes naturezas e dificulta a negociação de consensos e a definição de estratégias de governabilidade em Londrina.

Londrina faz parte de um conjunto de cidades com índices de desenvolvimento acima da média brasileira, mas que concentra grupos expressivos em situação de pobreza, e que habitam áreas com os piores indicadores sociais, cada vez mais distanciados dos grupos que mais concentram renda. As modificações no processo de urbanização da cidade vêm agravando uma série de problemas ligados à ocupação do solo e contribuiu para a formação de mosaicos bastante diferenciados e representativos da configuração dos territórios de exclusão, gerando uma cidade bastante complexa e pautada pela degradação dos seus recursos naturais e pela situação social desigual.

Essas misérias e superposições de carências nos territórios excluídos, em que se concentram grupos populacionais classificados nas relações desiguais como os "de baixo", usando a expressão de Thompson (1992), ou os "de fora" (outsiders), conforme Elias e Scotson (2000) - quase invisíveis para muitos grupos sociais com quadros de referência socioculturais e espaciais diferenciados -, vêm à tona quando são expostas na mídia como lugares de violência. É uma forma de reconhecimento às avessas. O que reforça a análise de Bourdieu (1989) para situar o espaço social e as diferenças objetivas que nele se desenham, como se fossem espontâneas, a funcionarem simbolicamente como espaço dos diferentes "estilos de vida" e que podem organizar o mundo social e contribuir para a manutenção e reprodução da violência. 
Essa situação de vulnerabilidade ou de insegurança das famílias forçadas a uma segregação espacial em bairros com alta concentração de pobreza é relevante em termos do avanço educacional, emprego, gravidez na adolescência e atividade criminal, pois envolvem os custos de moradia desproporcionais; distância entre moradia e emprego; moradia em situação irregular; moradia como fator de geração de renda; e os efeitos de vizinhança (TORRES, 2004; CARDIA, 2005).

A isso se acrescenta a existência dos "novos miseráveis" de hoje, que não são mais os tradicionais maltrapilhos, desempregados, abandonados, entre outros. Eles estão armados, são mão-de-obra barata, às vezes melhor remunerada que a inserida no mercado de trabalho legal. São novos miséráveis, segundo Passetti (1999, p.26), porque "habitam o mercado ilegal e, por vezes, co-habitam o mercado legal [...]. Desejam os bens de consumo a qualquer preço, desprezam os direitos sociais, buscam o bem-estar material pelo avesso do que o liberalismo pretende $[\ldots]$ ".

Desse modo, frente ao avanço da criminalidade organizada, uma possibilidade com graves consequências é que o Estado "social" se atrofie e o Estado "penal" se hipertrofie, passando a aumentar o investimento na criminalização da pobreza e, principalmente, dos jovens pobres cada vez mais isolados e estigmatizados nos bairros (WACQÜANT, 2001a).

\section{Considerações Finais}

$\mathrm{O}$ quadro atual da violência homicida em uma cidade média do interior do País mostra que os grupos jovens que sobrevivem com dificuldades cotidianas, que impedem a projeção de expectativas de vida mais amplas, são submetidos ao risco permanente do aniquilamento como última forma de controle social. Para uma parcela deles, resta como perspectiva a sobrevivência em meio à pobreza ou o envolvimento em esquemas de acentuada violência, em que a vida se torna artigo ou coisa sem valor.

A vida parece ter diferentes "pesos e medidas" quando se trata de representações sobre a violência homicida de jovens. A preocupação com as mortes de jovens parece emergir somente quando aquele que morre não pertence aos espaços socioespaciais segregados. A mídia, como agente cultural, tem uma posição importante nessa valoração da vida e da morte. A grande incidência de homicídios de jovens residentes em territórios segregados chama pouca atenção da opinião pública.

A vulnerabilidade dos jovens às mortes por arma de fogo se acentua quanto ao gênero, quando são solteiros, não estudam e nem trabalham. A grande incidência e a progressão dessas mortes tem forte relação com o tráfico de drogas e o lugar de moradia, onde encontra as condições propícias para a sua existência, pois é o espaço de produção e reprodução social. Mas não podemos desconsiderar a formação de outras territorialidades e espaços de poder a partir do envolvimento do jovem com a rede do tráfico de drogas.

O tipo de convivência que se estabelece entre os jovens da mesma faixa etária e a comunidade local pode determinar o envolvimento com o mundo da violência e da criminalidade. $O$ fato é que, no intrincado contexto social dos territórios de exclusão, os componentes simbólicos importam tanto quanto os aspectos objetivos para a iniciação de jovens na criminalidade.

Deve-se, assim, reter como referência o conceito de risco social ao qual estão submetidos determinados grupos de jovens que vivem nos territórios de exclusão da cidade. Como esse risco social não é um simples somatório dos riscos individuais das pessoas que ali residem, importa então analisar a relação entre as situações que envolvem os homicídios de jovens e as condições desses territórios.

Entre os aspectos centrais para avaliar a representação dos jovens e os projetos de 
políticas públicas para a juventude, em especial, no enfrentamento da insegurança, deve estar a preocupação da prevenção, multiplicação de serviços e de redução de riscos. Entendendo a juventude como uma categoria histórica, devem-se levar em conta as ideias, concepções e a experiência de um indivíduo ou de um grupo jovem, tendo como base as referências históricas regionais e locais.

Acidade, como um lugar de luta pela emancipação humana, constituiu esses territórios de exclusão e de homicídios pela incapacidade dos Poderes Públicos diagnosticarem a tempo a natureza da expansão da criminalidade, do narcotráfico e do comércio de armas, que se relacionam com a elevação das mortes de jovens. A inserção precária desses jovens em uma sociedade paralela os encerra em territórios de exclusão, fazendo com que eles continuem sem um lugar reservado na cidade, a não ser na rede de delitos e da morte precoce.

A intensificação de conflitos nas relações intersubjetivas ou interpessoais nos grupos jovens e que resultam em violência fatal, sinaliza que a sua integração no tráfico de drogas vem substituindo as tradicionais formas de socialização e vem a compor esse quadro de cidadania precária, demonstrando a perda ou a fraqueza da sensibilização e torna a violência homicida habitual e banal.

Com isso, os grupos jovens que correm maior risco de morrer em decorrência do homicídio estão imersos em uma cadeia produtiva de mercadorias e serviços que ultrapassam o seu lugar de moradia e de reprodução social, e que visam à manutenção de novas ou atualizadas formas de exploração e reprodução da violência. E o mercado segue inventando novos bens de consumo, incluindo as drogas, que acabam servindo de referência para a identificação e a socialização do jovem no grupo, além de suprir as necessidades essenciais não proporcionadas pelos meios convencionais.

A "juvenização" dos homicídios envolve não só a questão de gênero, vulnerabilidades e carências materiais, mas a reprodução simbólica das identidades que dissociam os jovens do contexto de promoção da cidadania associada à segurança urbana. O recurso à violência simbólica é um forte componente e quase uma regra nos grupos jovens. Às vezes tão importante quanto o valor atribuído à própria vida.

O poder público tem sido omisso ou pouco atuante nas questões que envolvem a segurança humana dos jovens e às condições que contribuem para a existência do risco individual e coletivo, isso faz do Estado o principal responsável pela violência homicida. De nada adiantarão as formas contemporâneas de vigilância e controle da realidade social dos grupos sociais se esse controle continuar servindo apenas para criminalizar a pobreza nos territórios de exclusão.

A mudança neste quadro só será possível quando a perda prematura de vida dos principais excluídos da cidade passar a ser considerada de fato e quando esses jovens efetivamente tiverem direito à cidade. Isso não significa isentar os jovens da responsabilidade pela violência por eles cometida, mas chamar a atenção para o desrespeito aos seus direitos institucionais, para que sejam efetivamente incluídos na agenda das políticas públicas locais e dos demais níveis.

\section{Referências}

ADORNO, S. F. Conflitualidade e violência: reflexões sobre a anomia na contemporaneidade. Revista Tempo Social, São Paulo, v. 10, n. 1, p. 1947, maio 1998.

ADORNO, S. F; BORDINI, E. B. T.; LIMA, R. S. O adolescente e as mudanças na criminalidade urbana. São Paulo em Perspectiva, Revista da Fundação SEADE, São Paulo, v. 13, n. 4, p. 62-74, out./dez., 1999.

ARBEX-JÚNIOR, J. Narcotráfico, um jogo de poder nas Américas. São Paulo: Moderna, 2001. (Coleção: Polêmica). 
ARGENTINA. Ministerio de Salud Publica. Anuário narcotráfico: 2006: Posadas: Província de Misiones, 2007. Disponível em: <http://www.igeo. ufrj.br/gruporetis/pdf/AnuarioNarcotrafico2006. pdf $>$. Acesso em: 25 out. 2007.

BAUMAN, Z. Modernidade líquida. Rio de Janeiro: Zahar Editora, 2001.

Vida para consumo: a transformação das pessoas em mercadoria. Tradução Carlos Alberto Medeiros. Rio de Janeiro: Zahar, 2008.

BOURDIEU, P. O poder simbólico. Rio de Janeiro: Ed. Bertrand, 1989.

CACCIA-BAVA, A.; COSTA, D. I. P. O lugar dos jovens na história brasileira. In: CACCIA-BAVA, A.; PÀMPOLS, C. F; CANGAS, Y. G. (Org.). Jovens na América Latina. São Paulo: Escrituras, 2004, p. 63 - 114.

CALDEIRA, T. P. R. Cidade de muros: crime, segregação e cidadania em São Paulo. 2. ed. São Paulo: 34/Edusp, 2003.

CARDIA, N. G. Jovens, violência fatal, superposição de carências e mercado de trabalho. São Paulo: NEV/USP, 2005. Disponível em: $<$ http:// www.nevusp.org>. Acesso em: 21 jun. 2007.

CARRARA, S. Singularidade, igualdade e transcendência: um ensaio sobre o significado social do crime. Araxá: ANPOCS, 1991. Disponível em: $<$ http://www.anpocs.org.br/portal/publicacoes $>$. Acesso em: 10 dez. 2007.

CENTRO BRASILEIRO DE INFORMAÇÕES SOBRE DROGAS PSICOTRÓPICAS - CEBRID. Departamento de Psicobiologia da Universidade Federal de São Paulo. Drogas psicotrópicas. São Paulo: CEBRID, 2003. Livreto Informativo.

DURKHEIM, E. O suicídio. São Paulo: Abril, 1978. (Coleção Os Pensadores).

ELIAS, N. O processo civilizador. Rio de Janeiro: Jorge Zahar, 1993. $2 \mathrm{v}$.

ELIAS, N.; SCOTSON, J. L. Os estabelecidos e os outsiders: Sociologia das relações de poder a partir de uma pequena comunidade. Rio de Janeiro: Jorge Zahar, 2000.

FEFFERMANN, M. Vidas arriscadas: o cotidiano dos jovens trabalhadores do tráfico. Petrópolis, RJ:
Vozes, 2006.

FOUCAULT, M. Em defesa da sociedade: Curso no College de France (1975-1976). São Paulo: Martins Fontes, 2000. (Coleção Tópicos).

GOIS, A. Para a antropóloga, apenas pobreza e desigualdade não explicam a ida de jovens para a criminalidade. Entrevista. Folha de São Paulo. São Paulo, 12 jul. 2004. p. A-12.

IANNI, O. Capitalismo, violência e terrorismo. Rio de Janeiro: Civilização Brasileira, 2004.

IBGE - INSTITUTO BRASILEIRO DE GEOGRAFIA E ESTATÍSTICA. Agregado de setores censitários dos resultados do universo. Censo Demográfico 2000. Rio de Janeiro: IBGE, 2002.

LEFEBVRE, H. Lógica formal lógica dialética. 5. ed. Rio de Janeiro: Civilização Brasileira, 1991.

LESSING, B. Demanda por armas de fogo no Rio de Janeiro. In: FERNANDES, R. C. (Coord.). Brasil: as armas e as vítimas. Rio de Janeiro: 7 Letras, 2005. p. 268 - 292.

LOLIS, D. Um jeito jovem de morrer: homicídios de jovens por armas de fogo em Londrina, 2000-2003. 2008. Tese (Doutorado em Sociologia) - Faculdade de Ciências e Letras, Programa de Pós-Graduação em Sociologia, Universidade Estadual Paulista Júlio de Mesquita Filho (Campus de Araraquara), Araraquara, 2008.

LONDRINA. Prefeitura Municipal. Companhia de Habitação de Londrina. Situação das favelas, assentamentos e ocupações urbanas de Londrina. Londrina: PML/COHAB, 2006.

MACHADO, L. O. Tráfico de drogas: bacia ParanáParaguai e São Paulo. Rio de Janeiro: UFRJ, 2002. Disponível em: $<$ http:/Www.igeo.ufrj.br/gruporetis/ gruporetis $>$. Acesso em: 23 out. 2007.

MALUF, N. A. Las subjetividades juveniles en sociedades en risco: un análisis en contextos de globalización y modernización. In: SEMINARIO LOS JÓVENES Y LA SOCIEDAD DE LA INFORMACIÓN. Globalización y Antiglobalización en Europa y América Latina, 2002, Lleida, Barcelona. 
MARTUCCELLI, D. Reflexões sobre a violência na condição moderna. Tempo Social: Revista de Sociologia da USP, São Paulo, v. 1, n. 11, p. 157175, maio 1999.

MICHAUD, Y. A violência. São Paulo: Ática, 2001. MOURA, R.; ULTRAMARI, C. O que é periferia urbana. São Paulo: Brasiliense, 1996. (Coleção Primeiros Passos).

OLIVEIRA, F. A questão do Estado: vulnerabilidade social e carência de direitos. Cadernos ABONG, São Paulo, n. 8, p. 6 -19, jun. 1995. Série As ONGs e a realidade brasileira.

OLIVEIRA, S. Anarquia e dissonâncias abolicionistas. Ponto-e-vírgula: revista eletrônica semestral do programa de estudos pós-graduados em ciências sociais da PUC-SP, São Paulo, v. 1, n.1, 2007. Disponível em: <http://www.pucsp.br/ ponto-e-virgula/n1/artigos/11-SaleteOliveira.htm $>$. Acesso em: 12 nov. 2007.

PASSETTI, E. (Coord.). Violentados: crianças, adolescentes e justiça. São Paulo: Imaginário, 1999.

PORTO, M. S. G. Da violência e de suas representações como respostas possíveis à impunidade. Mesa Redonda 33. Impunidade. Brasília, n. 15, p. 35 - 50, set./dez. 2001.

RAFESTIN, C. Por uma geografia do poder. São Paulo: Ática, 1993.

RIVERO, P. S. O mercado ilegal de armas de fogo na cidade do Rio de Janeiro. In: FERNANDES, R. C. (Coord.). Brasil: as armas e as vítimas. Rio de Janeiro: 7Letras, 2005. p. 197-267.

RODRIGUES, T. M. S. A infindável guerra americana: Brasil, EUA e o narcotráfico no continente. São Paulo em Perspectiva, São Paulo, v. 16, n. 2, p. 102-111, abr./jun. 2002.

ROLNIK, R. Exclusão territorial e violência. São Paulo em Perspectiva, São Paulo, v. 13, n. 4, p. 8291, out./dez. 1999.

SANTOS, M. Da totalidade ao lugar. São Paulo: Ed. da Universidade de São Paulo, 2005.

. Território e sociedade: entrevista com

Milton Santos. Entrevista concedida a Odette Seabra, Mônica de Carvalho e José Corrêa Leite. São Paulo: Fundação Perseu Abramo, 2000.
THOMPSON, E. P. A voz do passado: história oral. Rio de Janeiro: Paz e Terra, 1992.

TORRES, H. G. Segregação residencial e políticas públicas: São Paulo na década de 1990. Revista Brasileira de Ciências Sociais, São Paulo, v. 19 n. 54, p. 41-56, fev. 2004.

WACQÜANT, L. As prisões da miséria. Rio de Janeiro: Jorge Zahar, 2001a.

. Os condenados da cidade: estudo sobre marginalidade avançada. Rio de Janeiro: Revan: FASE, 2001b.

WAISELFISZ, J. J. Mapa da violência dos municipios brasileiros 2008. Brasília: RITLA/MS/ MJ; São Paulo: Instituto Sangari, 2008.

ZALUAR, A. Integração perversa: pobreza e tráfico de drogas. Rio de Janeiro: FGV, 2004.
Recebido em: abril de 2010

Aceito em: julho de 2010 